\title{
Bowel Injury following Lumbar Discectomy using Minimally Invasive Retractors
}

\author{
Aleksa Cenic, Niv Sne, Michael Lisi, Allan Okrainac, Kesava Reddy,
}

Can. J. Neurol. Sci. 2007; 34: 485-487

Prevalence of symptomatic lumbar disc herniation is $1-3 \%$ in the adult population. ${ }^{1}$ When conservative therapy (e.g., physiotherapy, anti-inflammatories, epidural injections, etc.) fails, open microsurgical discectomy is regarded as the treatment of choice. With this procedure, the incidence of injury to visceral bowel is reported to be 3.8 per 10,000 cases. $^{2}$ With the recent advent of tubular retractor systems, an increasing number of surgeons are using this minimally invasive procedure to replace traditional open microsurgical discectomy. The advantages include a smaller skin incision and a muscle splitting rather than muscle incising technique. As a result post-operative pain, blood loss and length of hospital stay may decrease significantly. ${ }^{3-6}$ Multiple studies have compared the two surgical techniques with regards to their clinical outcomes. ${ }^{6,7}$ The results of these studies reveal equal if not superior clinical outcomes with the minimally invasive technique. Despite the success of the minimally invasive microdiscectomy, none of the studies reported any intraoperative complications using this novel technique. This report represents the first documented bowel injury using METRx tubular retractors (Medtronic Sofamor-Danek, Memphis, TN) for minimally invasive lumbar microsurgical discectomy.

\section{Case Report}

\section{Clinical History}

A 36 year old female with severe back pain, and right lower limb radicular symptoms referred to Neurosurgery to assess for possible surgical intervention. Magnetic resonance imaging (MRI) of lumbar spine revealed L5-S1 paramedian disc herniation which was consistent with clinical findings (see Figures 1a \& 1b). Trial of conservative therapy was not effective hence, patient agreed to have lumbar discectomy done. The less invasive method of using METRx tubular retractors for the discectomy was offered to the patient. The patient agreed to the procedure upon discussion of potential benefits and possible complications.

\section{Minimally Invasive Microdiscectomy}

Under general anesthesia, the patient was placed prone on the Wilson frame. Using fluoroscopy, a Kirschner wire was docked onto the right side of the L5 lamina and a $1.5 \mathrm{~cm}$ skin incision was made. The METRx tubular retractor was then introduced in standard fashion over sequential dilators and the microscope brought in. Following laminotomy and removal of ligamentum flavum, the anticipated large disc herniation distorting the S1 nerve root was encountered. The disc was incised, and the

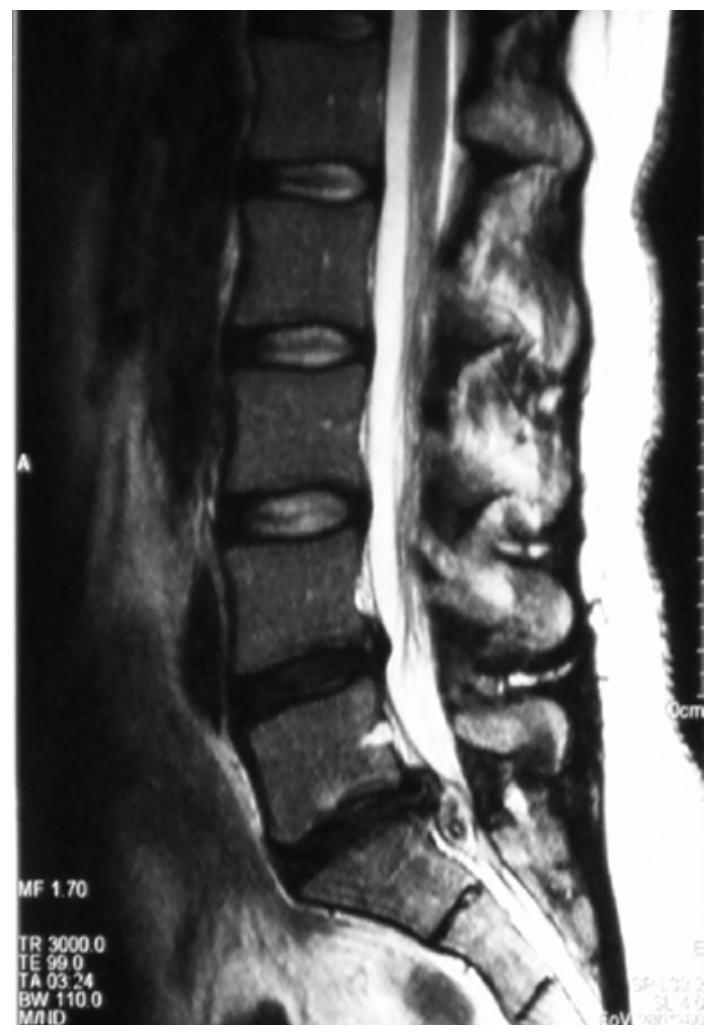

Figure 1a: Sagital T2 MRI image of lumbar spine. Large disc herniation at L5-S1 is noted with sequestered disc material inferiorly.

fragment removed with pituitary rongeurs. The end-plates of L5 and S1 were scraped using reverse-angled curettes. Copious bacitracin irrigation of the disc space was performed ensuring no residual loose disc pieces. Upon inspection, the nerve root was well decompressed. Hemostasis was achieved with bone wax

From the Division of Neurosurgery (AC, KR), Department of General Surgery (NS, ML, AO), McMaster University, Hamilton, Ontario, Canada.

ReCEIVED JANUARY 15, 2007. ACCEPTED IN FINAL FORM JUNe 2, 2007. Reprint requests to: Kesava Reddy, 644 Concession Street, Hamilton, Ontario, L8V 1B5, Canada. 


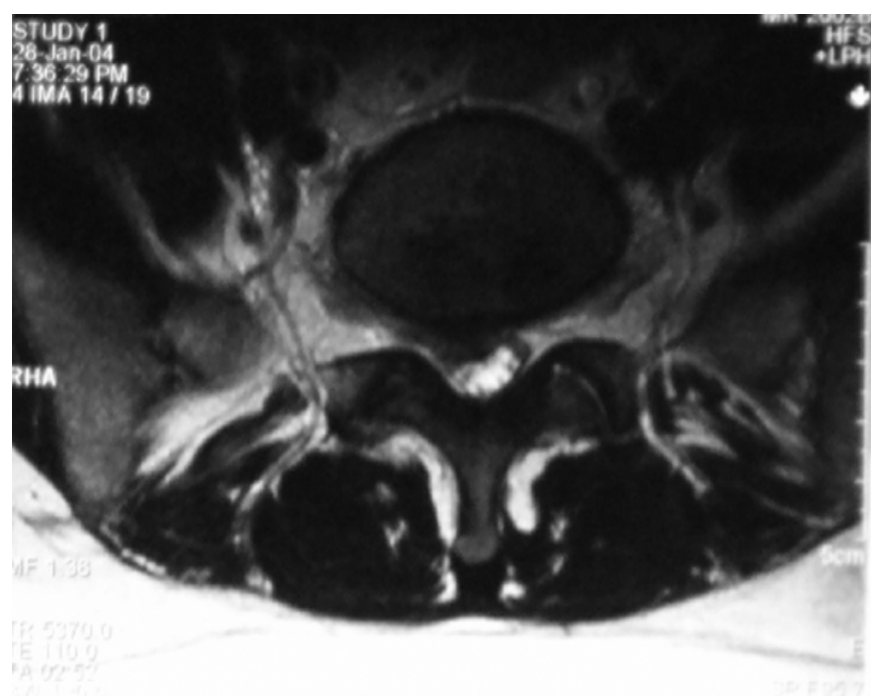

2USAI1

Figure 1b: Axial T2 MRI image of lumbar spine. Right paramedian protrusion of disc material at L5-S1 with significant compromise of S1 nerve root. the small intestine. The patient was returned to the post-operative anesthesia care unit.

On postoperative day one, the patient was discharged from hospital without any significant low back pain and radicular right leg pain. The patient was grossly intact with respect to right L5 or S1 motor examination. Pathological examination of the small bowel revealed a $4.5 \mathrm{~cm}$ segment of small bowel with a $2.0 \mathrm{~cm}$ perforation defect covered in fibropurulent exudates on the serosa. The patient was assessed in follow up and was found to have recovered well without any further complications.

\section{Discussion}

Inadvertent bowel perforation is a rare but well described complication of standard lumbar microdiscectomy. There have been 18 cases in the surgical literature reporting bowel injury ${ }^{2,8-15}$ Intestinal injury most frequently involved the ileum, with other injuries to sigmoid, cecum, appendix, and jejunum documented. Discovery of bowel injury rarely occurs intraoperatively, or in the recovery room., ${ }^{2,16}$ This delay in diagnosis partly explains the high morbidity and mortality associated with this complication. ${ }^{17}$ Our patient's injury was not investigated until post-operative day one, due to symptoms of worsening abdominal pain and distention. This is consistent with the time course of diagnosis in the literature. ${ }^{2}$

With the recent advent of tubular retractor systems for lumbar microdiscectomy, an increasing number of spine surgeons are changing from the standard "open" microdiscectomy to this more minimally invasive approach. This case report represents

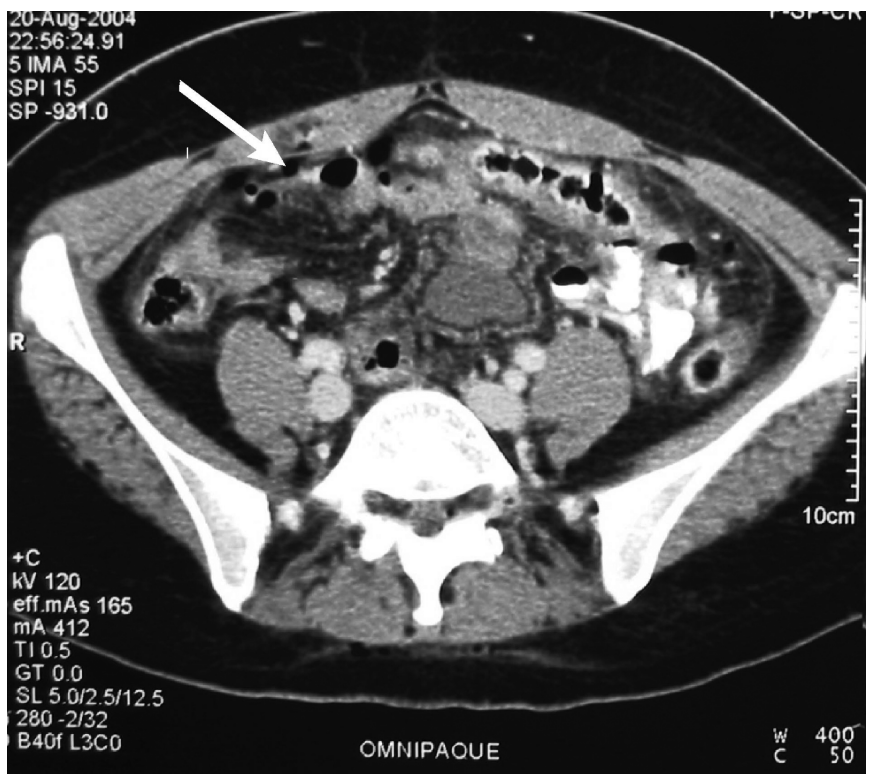

Figure 2: Axial CT image. Nonspecific large bowel wall thickening, and free intra-peritoneal air (white arrow), with slight peripheral enhancement. 
the first documented small bowel injury during lumbar microdiscectomy using minimally invasive tubular retractors.

In order to avoid intraoperative bowel injury, one must be aware and accustomed to the length of the tubular retractors when working with the long, bayonetted instruments (e.g., pituitary rongeur). The use of depth markers on these instruments will similarly serve as a precautionary strategy. Moreover by using the shortest possible retractor, one maximizes the working angle and minimizes the working depth. Additionally, one could avoid such injury by performing a sequestrectomy rather than a "radical" discectomy in order to avoid inadvertently plunging ventrally through the annulus fibrosus and the anterior longitudinal ligament. Overall, once accustomed to the instruments and technique, the surgeon should accept a supervised learning curve in order to minimize iatrogenic complications.

In conclusion, this case report illustrates that bowel injury continues to be a potential complication of lumbar microdiscectomy using minimally invasive tubular retractor systems. Finally, in the case of injury, early attention to patient symptoms, combined with early investigation such as radiographic imaging may allow for early detection to prevent significant morbidity and mortality.

\section{REFERENCES}

1. Andersson G. Epidemiology of spinal disorders. In: Frymoyer JW, Ducker TB, Hadler NM, Kostuik JP, Weinstein JN, Whitecloud TS, eds. The adult spine: principles and practice. New York, NY: Raven Press, 1997:93-141.

2. Smith EB, DeBord JR, Hanigan WC. Intestinal injury after lumbar discectomy. Surg Gynecol Obstet. 1991 Jul;173(1):22-4.

3. Palmer S. Use of a tubular retractor system in microscopic lumbar discectomy: 1 year prospective results in 135 patients. Neurosurg Focus. 2002 Aug 15;13(2):E5.

4. Perez-Cruet MJ, Foley KT, Isaacs RE, Rice-Wyllie L, Wellington R, Smith MM, et al. Microendoscopic lumbar discectomy: technical note. Neurosurgery. 2002 Nov;51(5 Suppl):S129-36.
5. Nakagawa H, Kamimura M, Uchiyama S, Takahara K, Itsubo T, Miyasaka T. Microendoscopic discectomy (MED) for lumbar disc prolapse. J Clin Neurosci. 2003 Mar;10(2):231-5.

6. Schizas C, Tsiridis E, Saksena J. Microendoscopic discectomy compared with standard microsurgical discectomy for treatment of uncontained or large contained disc herniations. Neurosurgery. 2005 Oct;57(4 Suppl):357-60.

7. Muramatsu K, Hachiya Y, Morita C. Postoperative magnetic resonance imaging of lumbar disc herniation: comparison of microendoscopic discectomy and Love's method. Spine. 2001 Jul 15;26(14):1599-605.

8. Kollbrunner F. Large intestine stenosis after laminectomy. [Article in German] Gastroenterologia. 1959;92:239-51.

9. Smith RA, Estridge MN. Bowel perforation following lumbar-disc surgery. Report of a case with a review of the literature. J Bone Joint Surg Am. 1964 Jun;46:826-8.

10. Birkeland IW Jr, Taylor TK. Bowel injuries coincident to lumbar disk surgery: a report of four cases and a review of the literature. J Trauma. 1970 Feb;10(2):163-8.

11. Shaw ED, Scarborough JT, Beals RK. Bowel injury as a complication of lumbar discectomy. A case report and review of the literature. J Bone Joint Surg Am. 1981 Mar;63(3):478-80.

12. Schwartz AM, Brodkey JS. Bowel perforation following microsurgical lumbar discectomy. A case report. Spine. 1989 Jan;14(1):104-6.

13. Goodkin R, Laska LL. Vascular and visceral injuries associated with lumbar disc surgery: medicolegal implications. Surg Neurol. 1998 Apr;49(4):358-70.

14. Hoff-Olsen P, Wiberg J. Small bowel perforation as a complication of microsurgical lumbar diskectomy. A case report and brief review of the literature. Am J Forensic Med Pathol. 2001 Sep;22(3):319-21.

15. Houten JK, Frempong-Boadu AK, Arkovitz MS. Bowel injury as a complication of microdiscectomy: case report and literature review. J Spinal Disord Tech. 2004 Jun;17(3):248-50.

16. Harbison SP. Major vascular complications of intervertebral disc surgery. Ann Surg. 1954 Sep;140(3):342-8.

17. Dixon JM, Lumsden AB, Piris J. Small bowel perforation. J R Coll Surg Edinb. 1985 Feb;30(1):43-6. 